\title{
The Effect of Nutrition Education and Medical Care Intervention Program on Food Insecurity and Dietary Protein Intake of Poor Pregnant Women in Rural Communities
}

\author{
Nweze Nnakwe, PhD, RDN, LDN \\ Illinois State University, Department of Family and Consumer Sciences, College of Applied Science and \\ Technology, US \\ *Corresponding Author: Nweze Nnakwe, Illinois State University, Department of Family and Consumer \\ Sciences, College of Applied Science and Technology, US
}

\begin{abstract}
Poor pregnant women can benefit from interventions that include nutrition education and medical care services that may prevent malnutrition, food insecurity, and promote positive pregnancy outcome. Food insecurity is asymptomatic measure of malnutrition. In Nigeria, malnutrition is one of the contributing factors to maternal and infant mortality. However, studies on the effect of free pre and postnatal medical care services and nutrition intervention in rural communities is limited. The aim of this study was to determine the effect of free medical care services and nutrition education on food insecurity and dietary protein intake of poor pregnant women participating in a community-based intervention program. Four hundred and ninety-nine pregnant women were recruited after they had enrolled in a community-based prenatal intervention program. The participants gave oral consent to be in the study. Participants responded to food frequency questionnaire and food security questions before and after the intervention program. Data were statistically analyzed using SPSS computer software. Pearson Chi-square was used to evaluate the differences between food insecurity levels and dietary protein and carbohydrate intake. Results show that food insecurity reduced significantly after the intervention program. The participants with high school education food security increased significantly more than those with less than high school education at $p<0.05$. In addition, food insecurity was associated with low dietary protein intake, but improved after the intervention $p<0.05$.
\end{abstract}

Keywords: Food Insecurity, Nutrition Education, Intervention Program, and Dietary Protein

\section{INTRODUCTION}

It is estimated in 2017 that globally 821 million people were malnourished, an increase from 804 million in 2016[1].Malnutrition is poor nutritional status due to dietary intake either above or below the optimal level. More than half of all child deaths worldwide are associated with malnutrition[2, 3].Micronutrient and protein-energy deficiencies are the most common form of malnutrition in developing countries.

Malnutrition affects a large proportion of pregnant women in many developing countries but has received minimum attention as an important determinant of poor maternal outcomes. Malnutrition is associated with intrauterine growth restriction, preterm birth, anemia, low birth weight, gestational diabetes and maternal and infant morbidity and mortality [4-6].

Food insecurity is often linked to poverty, and malnutrition. Food security means "access at all times by all people to an adequate amount of safe, nutritious, and culturally appropriate foods for active and healthy lives[7].Women contribute significantly to prevent food insecurity and malnutrition worldwide, especially in developing countries[8]. However, this contribution is overlooked and mostly uncompensated. Malnourished women in poverty bear sickly infants who cannot resist the diseases of poverty, and many die within the first years of life[9]. One child in six is born underweight, and 10 million die by age 5, half from malnutrition-related causes[10].

Maternal nutrition is one of the contributing factors to infants and maternal mortality, and influences fetal growth and eventual birth size[11].The fetus normal development is dependent on the mother's nutritional status. Protein-energy deficiency may occur suddenly or gradually. Protein-energy under nutrition (PEU), formally known as protein-energy malnutrition is the deficiency of all macronutrients 
[12].Maternal mortality, is a major cause of death among women of reproductive age in Nigeria and remains a serious public health issue [13]. Therefore, educating women on diet and providing them food supplements specially to undernourished mothers may reduce the possibility of maternal death. The purpose of this study was to determine the effect of free medical care services and nutrition education on food insecurity and dietary protein intake of poor pregnant women participating in a community-based intervention program.

\section{Method AND PROCEDURE}

Four hundred and ninety-nine poor pregnant women were recruited after they had enrolled in a community-based prenatal intervention program. The participants gave oral consent to be in the study and received a note containing the name of trained nurses they contacted for debriefing. Data was collected before and after the intervention program from participants who volunteered for three years using a questionnaire containing demographic characteristics, and Food Frequency questionnaire. In addition, participants responded to a six-question subscale of the 18 questions Food Security Module, developed by the United States Department of Agriculture (USDA). The subscale addressed the following areas: (1) not having enough money to buy food for a balanced meal (3 to4 times a day), (2) adults cutting the size or skipping meals, (3) worried that food would finish before getting money to buy food,(4) adults not eating for a whole day, and (5) how often this happened. Similarly, participants were screened for malaria and HIV infection and those that tested positive for malaria and HIV infection were treated; other health conditions were treated as they materialize throughout the pregnancy free of charge. In addition, they received routine vitamin and mineral supplements and dewarming medication. Participants were also provided transportation to and from the hospital for both pre and postnatal care service. They received education on nutrition, sanitary practices, and water purification methods.

\section{DATA ANALySis}

Data from each questionnaire were coded and statistical analyses were conducted using the Predictive Analysis Software for Windows (PAWS Statistics, version 18.0; SPSS Inc., Chicago, IL). Pearson's Chi-square test was utilized to evaluate the differences between food insecurity levels and dietary protein intake before and after the intervention program. Statistical significance was set at $\mathrm{p}<0.05$ level.

\section{Results}

Table1shows that food insecurity exists among participant in the intervention program but reduced after the intervention program. The difference between before and after the intervention program was statistically significant at $\mathrm{p}<0.05$.In Figure 1, participants who had less than high school education food insecurity was significantly higher than those who had high school or more education but improved after the intervention program at $\mathrm{p}<0.05$. Results also show that $73 \%$ of the participant did not eat for a whole day. However, after the intervention program only $26 \%$ skipped meal for a whole day. Results in Figure 2 show that participants dietary protein and carbohydrate intake were significant lower than the recommended amount but increased after the intervention program. Result also showed a lower protein intake in the participants that were more food insecure. Forty percent of the participants reported that they had received some sort of health education before they were enrolled in the program.

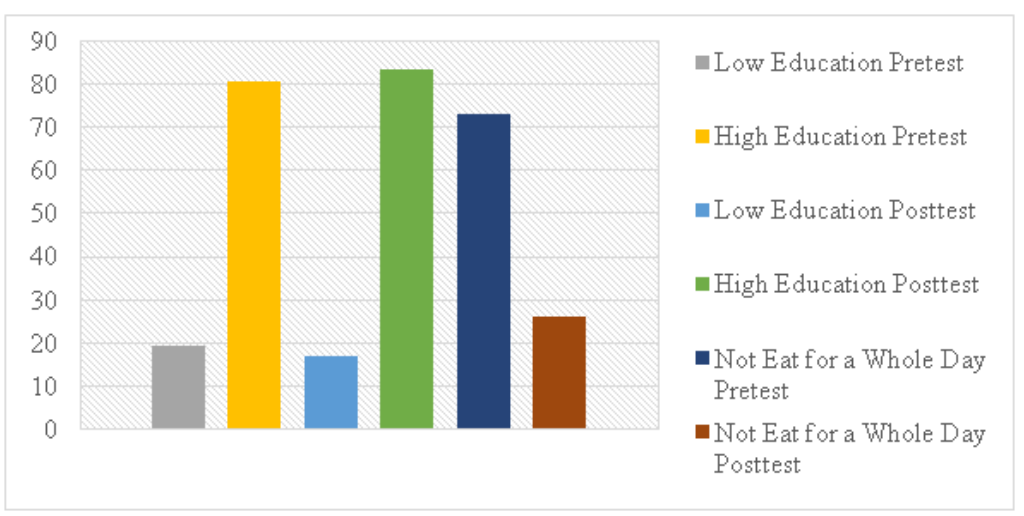

Figure1. The Prevalence of Food Insecurity and Education Level 
The Effect of Nutrition Education and Medical Care Intervention Program on Food Insecurity and Dietary Protein Intake of Poor Pregnant Women in Rural Communities

Table1. The Percent of Food Insecurity Among Participant in the Intervention Program

\begin{tabular}{|l|l|l|l|l|l|c|}
\hline & \multicolumn{3}{|c|}{ Pretest } & \multicolumn{3}{c|}{ Posttest } \\
\hline & Often & Sometimes & Never & Often & Sometimes & Never \\
\hline No Money to Buy Food & 4.6 & 58.9 & 14.3 & 2.4 & 53.7 & 43.9 \\
\hline Couldn't Afford Balanced Meals & 14.5 & 82.4 & 3.1 & 4.3 & 71.6 & 24.1 \\
\hline Cut Size of Meals or Skip Meals & 7.1 & 72.1 & 20.8 & 15.4 & 18.8 & 48.8 \\
\hline Worried Food Would Finish & 5.9 & 75.7 & 18.4 & 2.4 & 53.7 & 43.9 \\
\hline
\end{tabular}

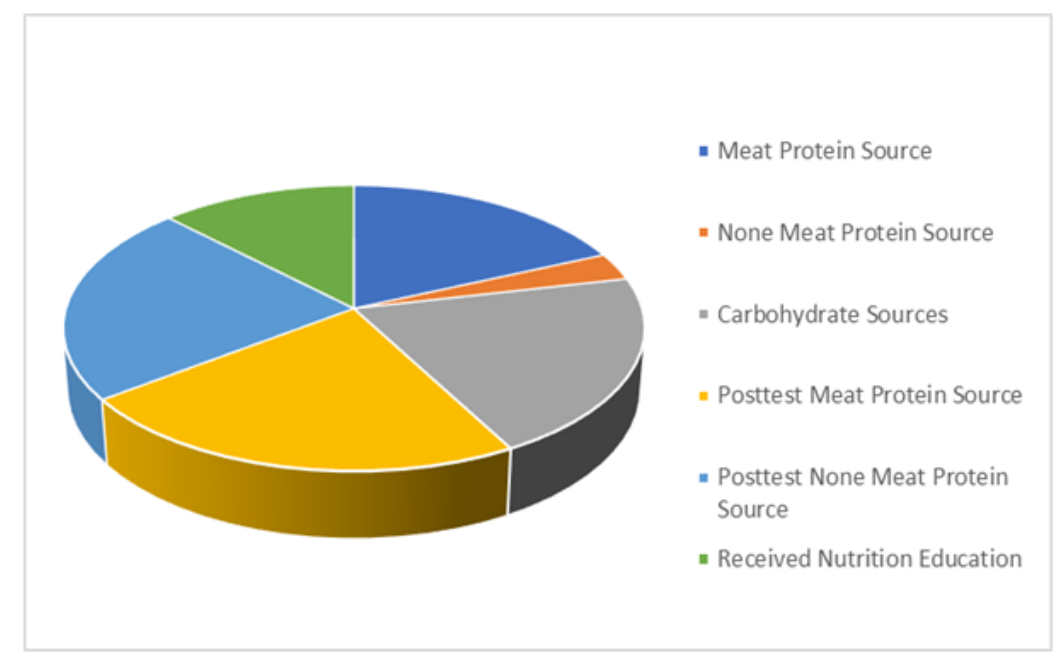

Figure2. Percentage of Carbohydrate and Protein Intake

\section{DISCUSSION}

This study aimed to determine the effect of providing nutrition education and medical care services on food insecurity and dietary protein intake of poor pregnant women participating in a communitybased intervention program. Results show that majority of the participants were food insecure but improved after the intervention program. Similarly, research studies have reported the incidence of food insecurity in pregnant women $[14,15]$.

The findings of this study showed an increase in food intake and food security in all the participants after the intervention program. A randomized community intervention trial of maternal vitamin A supplementation in Nepalese women showed a reduction in overall maternal mortality[16]. Results from this study also showed inadequate dietary protein and carbohydrate intake. Protein is an essential element of a healthy diet in humans that supports both growth and maintenance. Growth and development are very rapid during pregnancy and adequate dietary protein intake is very important for a healthy pregnancy outcome. [17]A study using 3744 women in the United States reported that food insecurity was associated with reduced micronutrient intake among women of childbearing age. Mean intakes of women from food-insecurity households were below two-thirds of the recommended daily allowance for calcium, iron, vitamin E, magnesium, and zinc, and women from these households were more likely to consume $<50 \%$ of the recommended energy intake than were those from food-secure households[18].In this study, food insecurity reduced in participants who attained high school or more education than those with less than high school education. Similarly, Berkman, et.al,[19] conducted systematic review and analyzes of the body of literature that has been produced regarding the relationship between literacy and health outcomes and the evidence about interventions intended to improve the health of people with low literacy. In general, they found a positive, significant relationship between literacy level and participants' knowledge of the health issues.

\section{CONCLUSION}

It is important to screen pregnant women for food security status for a better pregnancy outcome. This study shows that providing both nutrition education and free medical care services to poor pregnant women produced positive pregnancy outcome. Providing these services is an essential component in reducing infant and maternal morbidity and mortality. In addition, education attainment is essential for reducing food security and poor pregnancy outcome. 
The Effect of Nutrition Education and Medical Care Intervention Program on Food Insecurity and Dietary Protein Intake of Poor Pregnant Women in Rural Communities

\section{REFERENCES}

[1] (FAO), F.a.A.O.o.t.U.N., Building Climate Resilience for Food Security and Nutrition. 2018.

[2] Caulfield, L.E., Richard, S.A., AND Black, R.E., Undernutrition as an underlying cause of malaria morbidity and mortality in children less than five years old. Am. J. Trop. Med. Hyg, 2004. 71(2 suppl): p. 55-63.

[3] Mulholland, E.K., and Adegbola, R.A., Bacterial infections a major cause of death among children in Africa. N Engl J Med, 2005. 352: p. 75-77.

[4] Carmichael, S.L., Yang, W., Herring, A., Abrams, B., Shaw, GM., Maternal food insecurity is associated with increased risk of certain birth defects. J Nutr., 2007. 137(9): p. 2087-2092.

[5] Borders AE, G., W.A, Amsden, L.B, Holl, J.L., Chronic stress and low birth weight neonates in a lowincome population of women. Obstet Gynecol. , 2007. 109: p. 331-338.

[6] Laraia BA, S.-R., A.M., Gundersen, C., Dole N., Psychosocial factors and socioeconomic indicators are associated with household food insecurity among pregnant women. . J Nutr. , 2006. 136: p. 177-182.

[7] Coates, J., Frongillo, E.A., Lorge Rogers,B., Webb, P., Wilde, P.E., and Houser, r., Commonalities in the Experience of Household Food Insecurity across Cultures: What Are Measures Missing? J. Nutr, 2006. 136: p. 1438S-1448S.

[8] Kotzé, D.A., Role of women in the household economy, food production and food security: Policy guidelines. Outlook on Agriculture, 2003. 32(2): p. 111-121(11).

[9] Oldewage-Theron, W.W., A community-based integrated nutrition research programme to alleviate poverty: baseline survey. Public health, 2005. 119(4): p. 312-20.

[10] Organization., W.H., Nutrition risk factors meeting of interested parties.

[11] Luyckx, V.A., Barry, M. B., Birth weight, malnutrition and kidney-associated outcomes-a global concern. Nature Reviews Nephrology 2015. 11: p. 135-149

[12] M., J.E., Protein-Energy Undernutrition (PEU). 2018.

[13] Organization., W.H., Maternal and Child Mortality. 2018.

[14] Laraia, B.A., Siega-Riz, A.M., Gundersen, C., Household food insecurity is associated with self-reported pregravid weight status, gestational weight gain, and pregnancy complications. . J Am Diet Assoc. , 2010. 110: p. 692-701.

[15] Kimberly A Cullen Louise C Ivers $\square$, Food insecurity: special considerations for women $\square$ The Amer J of Clinic Nutri. , 2011. 94(6): p. 1740S-1744S.

[16] West K. P. Jr., K.J., Khatry S. K., et. al., Double blind, cluster randomised trial of low dose supplementation with vitamin A or beta carotene on mortality related to pregnancy in Nepal. The NNIPS2 Study Group. . BMJ 1999. 318: p. 570-575.

[17] Rajavel, E., and Ronald, O.B., Protein and Amino Acid Requirements during Pregnancy. Adv Nutr. , 2016. 7(4): p. 839S-844S. .

[18] Rose, D., Oliveira, V., Nutrient intakes of individuals from food-insufficient households in the United States. . Am J Public Health. , 1997. 87: p. 1956-1961.

[19] Berkman, N.D., et.al., Literacy and Health Outcomes: Summary. 2018.

Citation: Nweze Nnakwe. "The Effect of Nutrition Education and Medical Care Intervention Program on Food Insecurity and Dietary Protein Intake of Poor Pregnant Women in Rural Communities". International Journal of Humanities Social Sciences and Education (IJHSSE), vol 5, no.12, 2018, pp. 138-141. doi: http://dx.doi.org/10.20431/2349-0381.0512014.

Copyright: (c) 2018 Authors. This is an open-access article distributed under the terms of the Creative Commons Attribution License, which permits unrestricted use, distribution, and reproduction in any medium, provided the original author and source are credited. 